\title{
Post-Tensioning High-Hardness Rubber Damper System for Vibration Control of Residential Houses and Building Structures
}

\author{
AUTHOR(S): \\ Kim, Hyeong Gook; Yoshitomi, Shinta; Tsuji, \\ Masaaki; Takewaki, Izuru
}

\section{CITATION:}

Kim, Hyeong Gook ... [et al]. Post-Tensioning High-Hardness Rubber Damper System for Vibration Control of Residential Houses and Building Structures. Advances in Structural Engineering 2012, 15(12): 2157-2172

\section{ISSUE DATE:}

2012-12

URL:

http://hdl.handle.net/2433/168514

\section{RIGHT:}

(c) Multi-Science Publishing; This is not the published version. Please cite only the published version.; この論文は出版社版でありません。引 用の際には出版社版をご確認ご利用ください。 


\title{
Post-Tensioning High-Hardness Rubber Damper System for Vibration Control of Residential Houses and Building Structures
}

\author{
Hyeong Gook $\mathrm{Kim}^{1)}$, Shinta Yoshitomi ${ }^{2)}$, Masaaki Tsuji ${ }^{2)}$ and Izuru Takewaki ${ }^{2) *}$ \\ ${ }^{1)}$ Department of Urban and Environmental Engineering \\ ${ }^{2)}$ Department of Architecture and Architectural Engineering, \\ Graduate School of Engineering, Kyoto University, \\ Kyotodaigaku-Katsura, Nishikyo-ku, Kyoto 615-8540, Japan
}

\begin{abstract}
A new vibration control system including viscoelastic or viscoplastic rubber dampers is proposed for residential houses. This system consists of braces and a damper unit including a high-hardness rubber damper or a linear rubber damper. The high-hardness rubber damper possesses many unprecedented properties such as large stiffness, small temperature and frequency dependencies compared to most of usual viscoelastic dampers. Post tensioning forces are introduced into the braces to reduce small gap in joint parts and this system has high damping performance for micro-vibration. The control system can absorb sufficient energy through the high-rubber damper and post tensioning braces. A concept is introduced called an effective deformation ratio, i.e. the ratio of the actual damper deformation to the interstory drift of the frame, as a criterion to measure the damping performance and effectiveness of this system. To find out principal parameters that affect greatly the effective deformation ratio of the proposed new vibration control system, an incremental analysis method taking into account the geometrical and material nonlinearities is developed to simulate the main characteristics of this vibration control system. The accuracy of the analysis method is investigated through the comparison with the results by two simple analysis methods. The comparison with the experimental result is also conducted for further investigation.
\end{abstract}

Keywords : Vibration control, Post-tensioning system, High-hardness rubber damper, Effective deformation ratio, Geometrical and material nonlinearities, Incremental analysis

\footnotetext{
*Corresponding author: e-mail, takewaki@archi.kyoto-u.ac.jp
} 


\section{Introduction}

Residential houses sometimes encounter serious problems resulting from traffic and wind vibrations even though they have sufficient structural safety against earthquakes and typhoons. Damping systems consisting of braces and/or walls (Soong and Dargush 1997) are widely used as structural control systems in these houses. However some problems remain unresolved which are due to high cost and difficulty in control. The difficulty may come from the controllability in the range of micro-vibration. Another type of damper, i.e. tuned mass damper (TMD), is usually used in residential houses, but it has a difficulty in tuning. Recently, viscoelastic dampers which can improve the habitability as well as the safety are applied to a lot of structures (for example, see Zhang and Soong 1992, Aiken et al. 1993, Samali and Kwok 1995, Housner et al. 1997, Hanson and Soong 2001, Park 2001, Soong and Constantinou 2002, Min et al. 2004, Xu et al. 2003, 2004, Christopoulos and Filiatrault 2006, Takewaki 2009, Saidi et al. 2011).

The purpose of this paper is to propose a new vibration control system which has reliable advantages both in traffic and earthquake vibration with low cost and ease in installation. Especially, the most important thing is to propose a method capable of confirming simply the mechanism of a new vibration control system for evaluating a damping capacity. A concept is introduced called an effective deformation ratio, i.e. the ratio of the actual damper deformation to the interstory drift of the frame, as a criterion to measure the damping performance and effectiveness of this system. Also, an inverse problem approach is proposed to investigate the relation among the parameters and the effective deformation ratio.

A high-hardness rubber (Tani et al. 2008, 2009) for absorbing the energy in the range of micro to large amplitudes is introduced in the proposed new vibration control system. This high-hardness rubber produced by SRI Hybrid Corporation, Kobe, Japan was developed to capture high hardness, large stiffness, small temperature and frequency dependencies. Especially, while the high-hardness rubber shows elliptical hysteresis curves in the range of small deformation less than $5 \%$ of shear strain, it shows bilinear hysteresis curves in the range of more than $5 \%$ of shear strain.

In this paper, the accuracy of the analysis method is investigated through the comparison with the result by two simple analysis methods (Tsuji et al. 2010). The comparison with the experimental results (Tsuji et al. 2009) is also conducted to investigate the accuracy of the proposed incremental analysis method.

\section{Preliminary Analysis via Detailed Analysis Model}

\subsection{Outline of proposed vibration control system}

The proposed new vibration control system consists of post-tensioning braces using turnbuckles and a damper unit including a high-hardness rubber damper (Tani et al. 2008, 2009) as shown in Fig.1. This vibration control system has a damping capacity from the small strain range through the post-tension introduced by turnbuckles after setting this vibration control system in the frame.

The difference of the shear forces in the braces causes shear deformation of the high-hardness rubber. Also, two steel springs and up-down steel frames of the damper unit make the high-hardness rubber exhibit only horizontal shear deformation. The axial forces of the braces and the force in the damper unit are shown in Fig.2. 


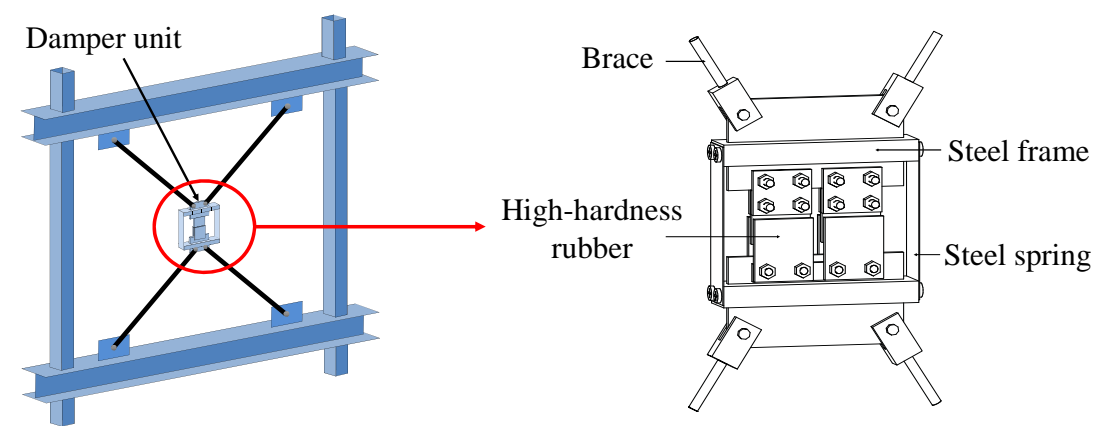

Fig.1 Outline of the proposed vibration control system
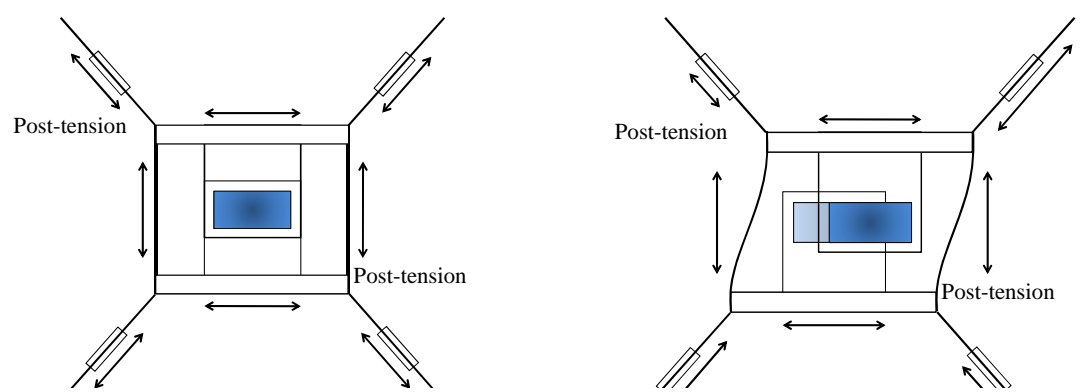

Fig.2 Post-tension in the proposed vibration control system

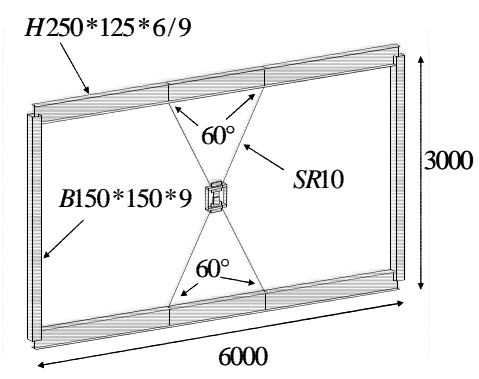

Fig.3 Detailed analysis model

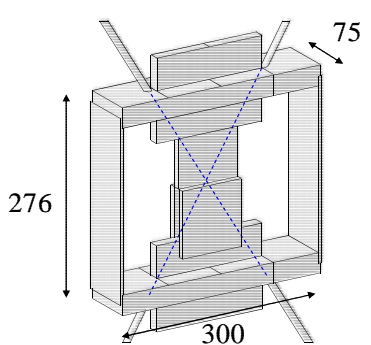

Fig.4 Damper unit

\subsection{Detailed analysis model}

A detailed analysis model is developed and constructed by a general-purpose computer software MIDAS. Figs. 3 and 4 show the overview and parameter values of the detailed analysis model. A pinned connection is used to permit rotation of the end of connected members, for examples beam-brace, steel frame-steel spring and brace-damper unit connections. The upper and lower steel frames placed in a damper unit (Fig.1 and 4) are set up as rigid elements. The two steel springs (shell element) connecting the upper and lower steel frames with a pinned connection have sufficient axial stiffness compared to braces (wire element). The shell elements; a high-hardness rubber and steel plates are perfectly tied together.

Two high-hardness rubbers inserted between three steel plates (double layer) have the thickness of $5 \mathrm{~mm}$ and the area of $80 \mathrm{~mm} \times 80 \mathrm{~mm}$. As shown in Fig.3, the diameter of braces is $10 \mathrm{~mm}$, and the installation angle $\theta$ of braces is 60 degree. There is no eccentricity between the braces and the post-tension introduced is $7000 \mathrm{~N}$. The parameters of the detailed analysis model 
are set up based on a one-story residential house made of steel frames.

The high-hardness rubber used in this research has small temperature and frequency dependency compared to general visco-elastic dampers. While the high-hardness rubbers show elliptical hysteretic curves in the small deformation range less than $5 \%$ of shear strain, they show bilinear hysteretic curves in the range of more than $5 \%$ of shear strain. But it has remarkable strain dependency. The mechanical modeling of high-hardness rubber dampers has been proposed by Tani et al. (2008, 2009). The equivalent stiffness $k_{e q}[N / \mathrm{mm}]$ and damping coefficient $c_{e q}[\mathrm{Ns} / \mathrm{mm}]$ of high-hardness rubber dampers are described respectively, as follows (Suzuki et al. 2007).

$$
\begin{aligned}
& k_{e q}=\frac{S}{t}\left(\frac{0.32+0.11 \varepsilon^{0.38}}{1+\varepsilon} \bar{\gamma}_{\max }^{-0.62}+\frac{0.32 \varepsilon-0.11 \varepsilon^{0.38}}{1+\varepsilon} \frac{\bar{\gamma}_{\max }^{0.38}}{\gamma_{\max }}+0.10 \gamma_{\max }{ }^{-0.66}\right) \\
& c_{e q}=\frac{S}{t}\left(\frac{0.64 \varepsilon-0.22 \varepsilon^{0.38}}{\pi \omega} \frac{\bar{\gamma}_{\max }^{0.38}}{\gamma_{\max }}+\frac{0.306}{2 \pi^{2}}\left(\frac{\omega}{2 \pi}\right)^{-0.75} \gamma_{\max }^{-0.75}\right)
\end{aligned}
$$

where

$$
\varepsilon=\frac{0.94\left|\gamma_{\max }\right|^{0.73}}{\left|\gamma_{\max }\right|^{0.73}+0.01}
$$

In Eqs.(1)-(3), $S$ and $t$ are the area $\left[\mathrm{mm}^{2}\right]$ and the thickness $[\mathrm{mm}]$ of the high-hardness rubber, $\bar{\gamma}_{\max }$ is the maximum shear strain experienced so far and $\gamma_{\max }$ is the maximum shear strain in the current loop. On the other hand, $c_{e q}$ is not used in this paper because of dealing with only static response.

\subsection{Results by detailed analysis model}

Figs.5-7 show the relation of shear strain of the high-hardness rubber, the amount of rotation of the damper unit and the axial force of braces, respectively, with respect to the prescribed interstory drift in the range of 0 to $20 \mathrm{~mm}$. Fig. 5 shows the relation of shear strain of the high-hardness rubber to the prescribed interstory drift which is almost linear in the wide range of deformations. However nonlinearity can be observed in the small strain range. This result shows that the high-hardness rubber has a damping capability from a small deformation range. The amount of rotation of the damper unit becomes large with the increase of frame deformation. However, the amount of rotation of the damper unit is very small and is 0.03 radians even under large frame deformation (interstory drift) of $20 \mathrm{~mm}$. Therefore, the loss of deformation (effectiveness) of the high-hardness rubber due to the rotation of the damper unit can be neglected. In addition, the post-tension introduced to the braces is decreased from $7000 \mathrm{~N}$ to $4000 \mathrm{~N}$ due to the beam flexibility of the frame. If the decrease of post-tension by the beam flexibility of the frame is considered, the post-tension will be lost in the smaller deformation than expected and the braces without post-tension do not work. 


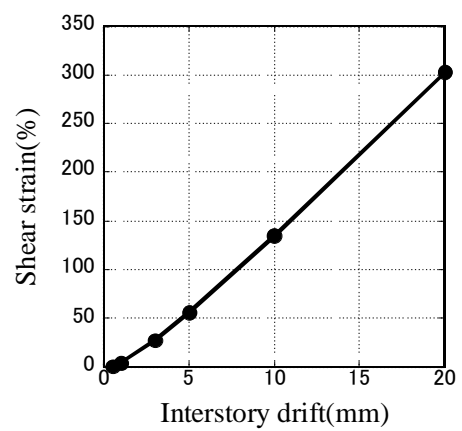

Fig.5 Shear strain of high-hardness rubber

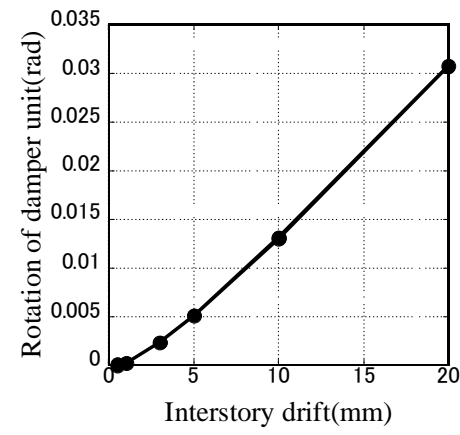

Fig.6 Amount of rotation of damper unit

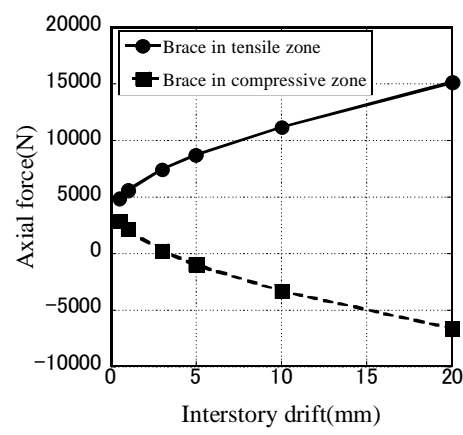

Fig.7 Axial force of brace

\section{Evaluation of Effective Deformation Ratio of New Vibration Control System via Spring Model}

In this section, a spring model (Tsuji et al. 2010) is introduced to explain the mechanism of the new vibration control system on the assumption that the damper unit does not rotate. This spring model is simpler than the detailed analysis model in the previous section and is appropriate in the early stage of design.

\subsection{Spring model}

To express the deformation of the damper unit shown in Fig.8, we introduce a simplified model called a spring model as shown in Fig.9. First of all, we assume that the shear deformation of the high-hardness rubber is the same as the deformation of the damper unit and the ends of the steel plates in the damper unit are displaced in the horizontal direction only without rotation. In other words, the vertical displacement of the end of braces, the rotation of the damper unit and the displacement of the frame by beam flexibility are neglected.

\subsection{Formulation of spring model}

The elongation $\Delta L$ of the braces in tensile or compressive zone may be expressed as

$$
\Delta L=T_{b} / K_{b}
$$

where $T_{b}$ is the tensile force of the braces after the deformation and $K_{b}$ is the axial stiffness (=EA/L ). In addition, $E, A, L$ are the elastic modulus, the cross-sectional area and the initial length of the brace, respectively. 


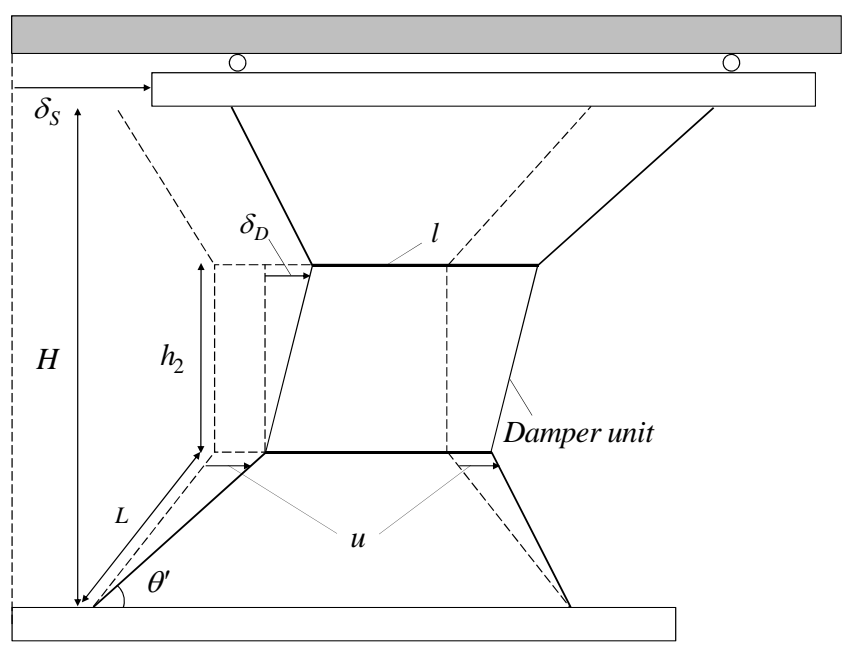

Fig.8 Deformed shape of damper unit (Rotation neglected)

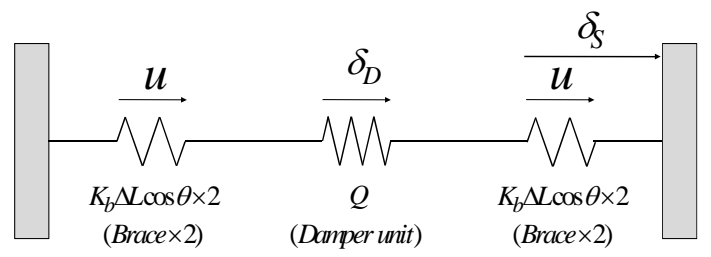

Fig.9 Spring model

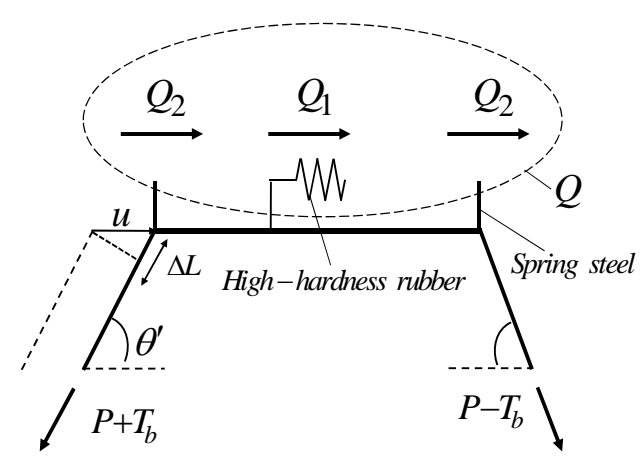

Fig.10 Free-body diagram in spring model

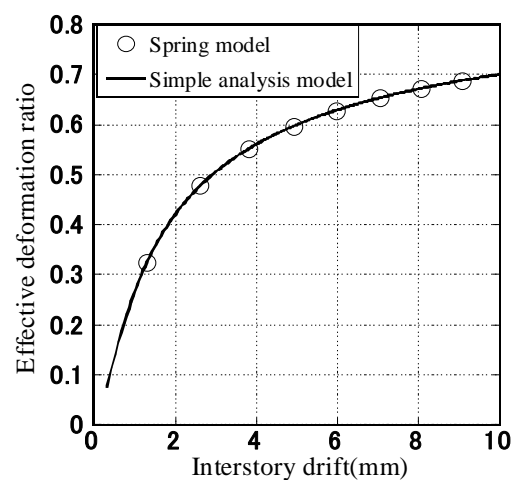

Fig.11 Relation between interstory drift and effective deformation ratio

With the help of Fig.10, we can derive

$$
T_{b}=\left(Q_{1}+2 Q_{2}\right) /(2 \cos \theta)=Q /(2 \cos \theta)
$$

where $Q_{1}$ is the shear force in the high-hardness rubber, $Q_{2}$ is the shear force in the steel plate and $Q$ is the total shear force in the damper unit. The horizontal displacement $u$ of the end of 
the brace is obtained from the relation between the elongation $\Delta L$ and the installation angle $\theta$ of braces.

$$
u=\Delta L /(\cos \theta)
$$

The total displacement $\delta_{S}$ of the frame can then be expressed as follows as the sum of the horizontal displacement $u$ of the end of braces and the deformation $\delta_{D}$ of the damper unit.

$$
\delta_{S}=\delta_{D}+2 u
$$

\subsection{Definition of effective deformation ratio}

A concept is introduced called an effective deformation ratio, i.e. the ratio of the actual damper deformation to the interstory drift of the frame $\left(=\delta_{D} / \delta_{S}\right)$, as a criterion to measure the damping performance and effectiveness of this system.

\subsection{Inverse-problem method of effective deformation ratio by spring model}

Substituting Eqs.(4)-(6) into Eq.(7), the effective deformation ratio is obtained as

$$
\frac{\delta_{D}}{\delta_{S}}=\frac{\cos ^{2} \theta}{\cos ^{2} \theta+\frac{Q}{K_{b} \delta_{D}}}
$$

In the ordinary analysis, the deformation $\delta_{D}$ of the damper unit is calculated from the frame deformation $\delta_{S}$. However in a simple analysis model such as the spring model, the frame deformation $\delta_{S}$ can be calculated from a specified value of $\delta_{D}$. In this process, the stiffness of the high-hardness rubber and the shear force of the damper unit are used. In other words, the effective deformation ratio can be obtained by substituting the shear force $Q$ in the damper unit corresponding to $\delta_{D}$ and the equivalent stiffness $K_{e q}$ of the high-hardness rubber into Eq.(8). This method based on an inverse problem formulation enables one to avoid repetitive calculation.

Fig. 11 shows the effective deformation ratio by a spring model. The parameter values of the spring model are taken from the detailed analysis model. In addition, the effective deformation ratios of the spring model are compared with those of the simple analysis model shown in Fig.12.

\section{Simple Analysis Model Considering Rotation of Damper Unit}

\subsection{Simple analysis model}

Based on the results by the detailed analysis model, it can be observed that the rotation of the damper unit affects the damping capacity of the proposed vibration control system. Fig.12 shows a simple analysis model considering rotation of the damper unit. We assume that the shear deformation of the high-hardness rubber is the same as the shear deformation of the damper unit and the beam in the frame as well as the horizontal steel plates in the damper unit are rigid. We further assume that the height of the damper unit does not change in the process of deformation and the damper unit is deformed in the anti-symmetric shape. 


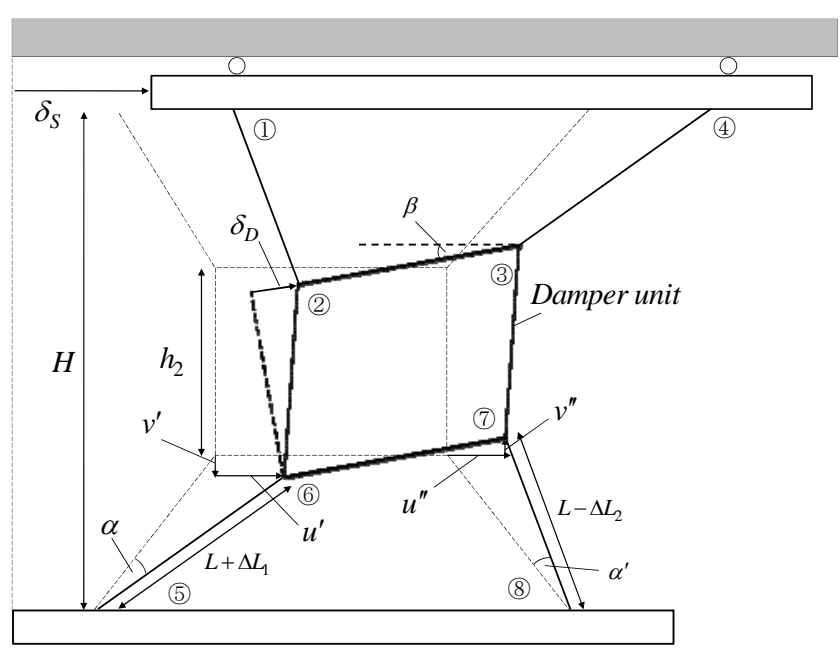

Fig.12 Simple analysis model

\subsection{Geometrical relation and equilibrium equation}

$\alpha, \alpha^{\prime}, \beta$ are the rotational angles of the braces in the tensile and compressive zones and the rotational angle of the damper unit, respectively. $l$ is the width of the damper unit. Considering the rotation of the horizontal steel plates in Fig.12, the horizontal and vertical displacements of the ends of the horizontal steel plates (also the ends of the braces) are obtained as

$$
\begin{gathered}
u^{\prime}-u^{\prime \prime}=l(1-\cos \beta) \\
v^{\prime}+v^{\prime \prime}=l \sin \beta
\end{gathered}
$$

Through the geometrical relation between the node (5) and (6) of the brace in the tensile zone, we can rewrite $u^{\prime}$ and $v^{\prime}$ as follows.

$$
\begin{aligned}
& u^{\prime}=\left(L+\Delta L_{1}\right) \cos (\theta-\alpha)-L \cos \theta \\
& v^{\prime}=L \sin \theta-\left(L+\Delta L_{1}\right) \sin (\theta-\alpha)
\end{aligned}
$$

Furthermore, from those of the relation between the node (7) and (8) of the brace in the compressive zone, we can rewrite $u^{\prime \prime}$ and $v^{\prime \prime}$ as follows.

$$
\begin{aligned}
& u^{\prime \prime}=L \cos \theta-\left(L-\Delta L_{2}\right) \cos \left(\theta+\alpha^{\prime}\right) \\
& v^{\prime \prime}=\left(L-\Delta L_{2}\right) \sin \left(\theta+\alpha^{\prime}\right)-L \sin \theta
\end{aligned}
$$

where $u^{\prime}$ and $v^{\prime}$ are the horizontal and vertical displacement of the end node of the brace in the tensile zone, respectively. On the other hand, $u^{\prime \prime}$ and $v^{\prime \prime}$ are the horizontal and vertical displacement of the end node of the brace in the compressive zone. $\Delta L_{1}$ is the elongation of the brace in the tensile zone and $\Delta L_{2}$ is the elongation of the brace in the compressive zone.

The horizontal force in the damper unit can be obtained as follows from the equilibrium of forces acting in the rotated damper unit and two braces as shown in Fig.13. 


$$
Q \cos \beta=\left(P+T_{b 1}\right) \cos (\theta-\alpha)-\left(P-T_{b 2}\right) \cos \left(\theta+\alpha^{\prime}\right)
$$

Similarly, the vertical force in the damper unit can be obtained as follows from the equilibrium of forces acting in the rotated damper unit and two braces as shown in Fig.13.

$$
Q \sin \beta+2 P \sin \theta \cos \beta=\left(P+T_{b 1}\right) \sin (\theta-\alpha)+\left(P-T_{b 2}\right) \sin \left(\theta+\alpha^{\prime}\right)
$$

where $P$ is the post-tensioning force, $T_{b 1}$ is the increased force in the tensile-zone brace and $T_{b 2}$ is the decreased force in the compressive zone brace. $2 P \sin \theta$ in Eq.(16) shows the sum of the axial forces in the vertical steel plates. In the analysis of the simple analysis model, we assume that the axial forces of the vertical steel plates do not change in the deformation process.

From the equilibrium of moments around the point $O$, i.e. the center of the damper unit, Eq.(17) can be obtained.

$$
\left(P+T_{b 1}\right) \times e_{1}=\left(P-T_{b 2}\right) \times e_{2}
$$

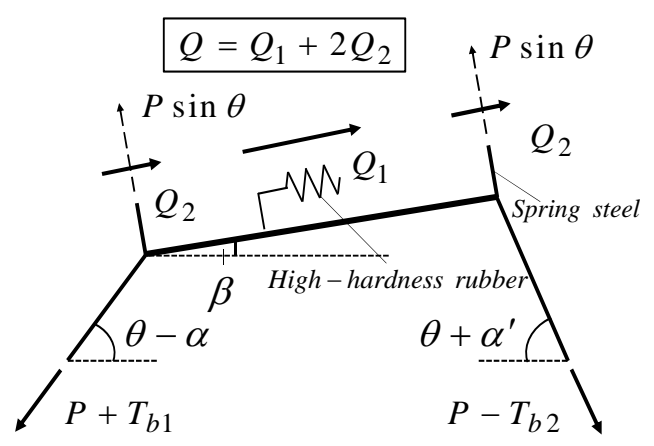

Fig.13 Equilibrium of forces in damper unit Fig.14 Moment equilibrium in damper unit

In Eq.(17), $e_{1}, e_{2}$ are the eccentricities of the braces as shown in Fig.14.

$$
\begin{aligned}
& e_{1}=\left(l-\frac{h_{2}}{\tan (\theta-\alpha-\beta)}+D\right) \sin (\theta-\alpha-\beta) \\
& e_{2}=\left(l-\frac{h_{2}}{\tan \left(\theta+\alpha^{\prime}+\beta\right)}-D\right) \sin \left(\theta+\alpha^{\prime}+\beta\right)
\end{aligned}
$$

\subsection{Inverse-problem solution for simple analysis model}

In case of no eccentricity of braces as shown in Fig.15, the rotational angles $\alpha, \alpha^{\prime}$ of the braces become less than 0.013 radian when the maximum story deformation angle $\left(1 / 150=\delta_{S} / H\right)$ is specified in the detailed analysis model. In this case, it may be possible to use a linear approximation in the simple analysis model. This assumption may be used even in case where the eccentricity exists in the braces. 


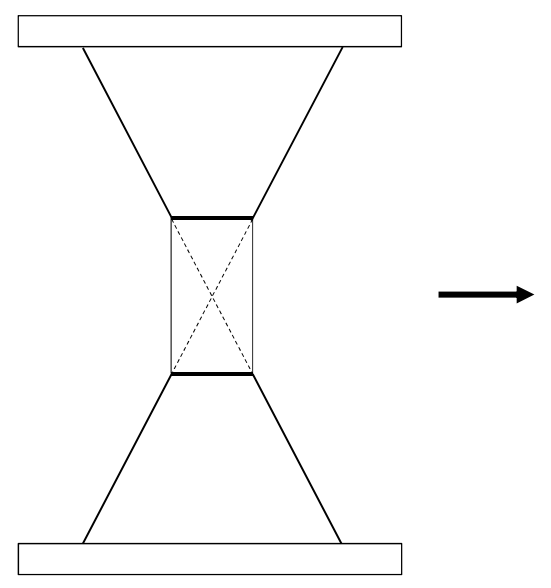

(a) No eccentricity model

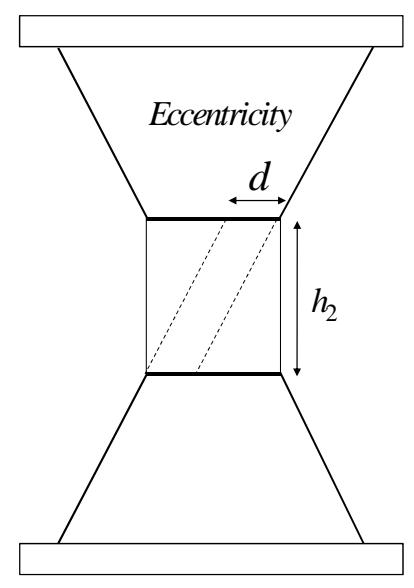

(b) Eccentric model

Fig.15 Definition of eccentricity

With the application of the linear approximation to Eqs.(9)-(19) and the substitution of Eqs.(9)-(14), and (18), (19) into Eqs.(15)-(17), the following equations can be obtained.

$$
\begin{gathered}
\alpha=\frac{F-(C E / B)}{D-(A E / B)} \\
\alpha^{\prime}=\frac{F-(C D / A)}{E-(B D / A)}
\end{gathered}
$$

where

$$
\begin{gathered}
A=\bar{c}+\frac{2 L}{l} \bar{c}^{2}+\frac{\bar{s}^{2}}{\bar{c}}+\frac{2 P \bar{s}^{2}}{K_{b} l}+\frac{2 Q \bar{c}}{K_{b} l}+\frac{2 K_{b} L \bar{s}^{2}}{Q}+\frac{2 P \bar{c}^{2}}{Q} \\
B=\bar{c}+\frac{2 L}{l} \bar{c}^{2}+\frac{\bar{s}^{2}}{\bar{c}}+\frac{2 P \bar{s}^{2}}{K_{b} l}-\frac{2 Q \bar{c}}{K_{b} l}-\frac{2 K_{b} L \bar{s}^{2}}{Q}-\frac{2 P \bar{c}^{2}}{Q} \\
C=\frac{2 Q \bar{s}}{K_{b} l} \\
D=2 P\left(l \bar{c}+h_{2} \bar{s}\right)\left\{\overline{S C}\left(1+\frac{2 L \bar{c}}{l}\right)+2 \frac{P \bar{s}^{3}}{K_{b} l}+2 \overline{s c} \frac{Q}{K_{b} l}\right\} \\
+2 P\left(I \bar{s}-h_{2} \bar{c}\right) \bar{s}^{2}+Q\left\{2 l \overline{s c}-h_{2}\left(\bar{c}^{2}-\bar{s}^{2}\right)\right\}
\end{gathered}
$$




$$
\begin{gathered}
E=2 P\left(l \bar{c}+h_{2} \bar{s}\right)\left\{\overline{s C}\left(1+\frac{2 L \bar{c}}{l}\right)+2 \frac{P \bar{s}^{3}}{K_{b} l}-2 \overline{s C} \frac{Q}{K_{b} l}\right\} \\
+2 P\left(l \bar{s}-h_{2} \bar{c}\right) \bar{s}^{2}-Q\left\{2 l \overline{s C}-h_{2}\left(\bar{c}^{2}-\bar{s}^{2}\right)\right\} \\
F=2 Q \bar{s}\left(l \bar{s}-h_{2} \bar{c}\right)+4 P \bar{s}^{2}\left\{D \bar{c}+\left(l \bar{c}+h_{2} \bar{s}\right) \frac{Q}{K_{b} l}\right\} \\
\bar{s}=\sin \theta, \bar{c}=\cos \theta
\end{gathered}
$$

When the deformation $\delta_{D}$ of the damper unit is given, the shear force $Q$ acting in the damper unit is determined by using the sum of the equivalent stiffness of the high-hardness rubber and the horizontal stiffness of vertical steel plates. By substituting the shear force $Q$ into Eqs.(20) and (21), $\alpha$ and $\alpha^{\prime}$ can be obtained. Furthermore, the rotational angle $\beta$ of the damper unit is determined from the relationship among Eqs.(12), (14) and (10).

This simple analysis model called the inverse-problem analysis method has a merit that it does not need the repetitive calculation of deformation of the damper unit and equivalent stiffness of the nonlinear high-hardness rubber.

\subsection{Parametric study}

Several parametric studies are conducted to examine the effect of elements comprising the proposed damper system on the effective deformation ratio by the simple analysis model.

\section{(a) Effect of post tension on effective deformation ratio}

2, 20 and 200\% of shear strain, respectively, are given to a high-hardness rubber damper first. Then the variation of the effective deformation ratio with respect to the introduced post tension is examined in each case. Fig.16 (a) shows the effective deformation ratio is not affected by the introduced post tension. However the effect of buckling behavior on braces is not considered in the simple analysis model. To confirm the effective analysis range of the proposed analytical models, it is necessary to examine the story drift when the buckling behavior of braces begins from experiments.

\section{(b) Effect of installation angle of braces on effective deformation ratio}

Fig.16 (b) plots the effective deformation ratio with respect to the installation angle of braces in case of that the shear strains of a high-hardness rubber are given as 2, 20 and 200\%, respectively. It is known that the optimal installation angle of braces exists, which maximizes the effective deformation ratio, and the optimal angles in each case are about 35 degrees.

\section{(c) Effect of eccentricity in braces on effective deformation ratio}

Fig.16 (c) and (d) indicate the effective deformation ratio and the rotational angle of a damper unit with respect to the shear strain of a high-hardness rubber damper, in case where the eccentricity exists in the braces. These results present that the eccentricity in braces make the rotational angle of braces larger, and it eventually reduces the effective deformation ratio. 


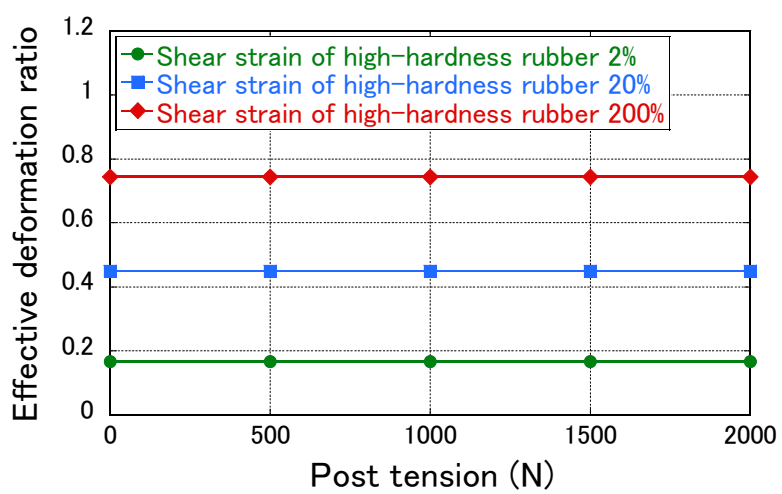

(a) Effective deformation ratio versus post tension

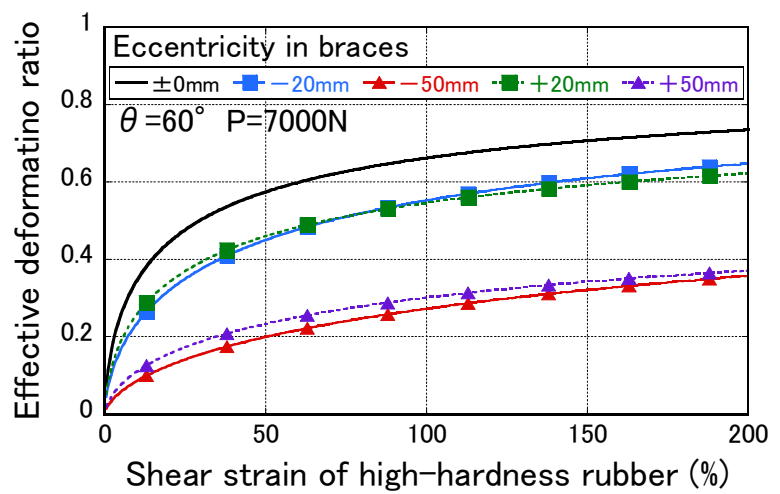

(c) Effective deformation ratio versus shear strain of high-hardness rubber

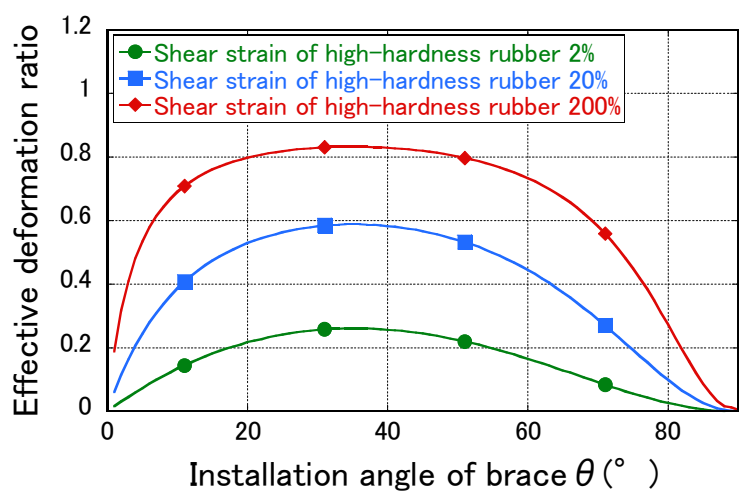

(b) Effective deformation ratio versus installation angle of brace

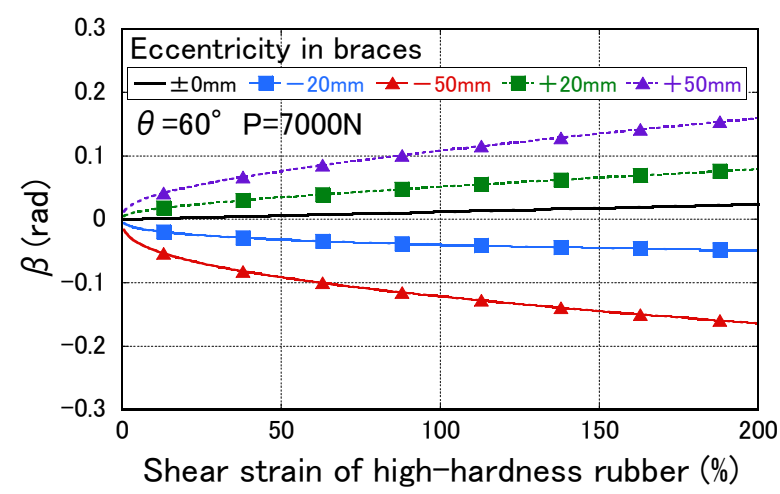

(d) Rotational angle of damper unit versus shear strain of high-hardness rubber Fig.16 Results of parametric study

\section{Incremental Analysis Method Taking into Account Geometrical and Material Nonlinearities}

\subsection{Incremental analysis method}

This incremental analysis method using $\delta_{D}$ as a principal parameter is aimed at incrementally calculating the nonlinear equations (9), (10), (15), (16), (17) using the equivalent linearization of these equations. First of all, we differentiate these nonlinear equations by the parameter $\delta_{D}$. Through this incremental analysis method, we can predict the changes of the elongation and rotational angle of braces, the rotational angle of the damper unit and the effective deformation ratio of the proposed system according to the increase of shear deformation of the damper unit from its initial state $\left(\delta_{D}=0\right)$. A general-purpose computer software MATLAB is used in this incremental analysis and parameter values used in this method are the same as those in the simple analysis model.

\subsection{Incremental formulation of nonlinear equations}

Incremental analysis for unknown quantities is performed to get the analytical solutions of the shear deformation $\delta_{D}$ of the damper unit. Substituting Eqs.(11)-(14) into Eqs.(9) and (10), Eqs.(18) and (19) into Eqs.(17), Eq.(4) into Eqs.(15) and (16), respectively, five simultaneous 
equations including five unknown quantities and constants are obtained as follows.

$$
\begin{gathered}
\left(L+\Delta L_{1}\right) \cos (\theta-\alpha)-L \cos \theta-L \cos \theta+\left(L-\Delta L_{2}\right) \cos \left(\theta+\alpha^{\prime}\right)=l(1-\cos \beta) \\
L \sin \theta-\left(L+\Delta L_{1}\right) \sin (\theta-\alpha)+\left(L-\Delta L_{2}\right) \sin \left(\theta+\alpha^{\prime}\right)-L \sin \theta=l \sin \beta \\
Q \cos \beta=\left(P+E A \frac{\Delta L_{1}}{L}\right) \cos (\theta-\alpha)-\left(P-E A \frac{\Delta L_{2}}{L}\right) \cos \left(\theta+\alpha^{\prime}\right) \\
Q \sin \beta+2 P \sin \theta \cos \beta=\left(P+E A \frac{\Delta L_{1}}{L}\right) \sin (\theta-\alpha)+\left(P-E A \frac{\Delta L_{2}}{L}\right) \sin \left(\theta+\alpha^{\prime}\right) \\
\left(P+E A \frac{\Delta L_{1}}{L}\right) \cdot e_{1}=\left(P-E A \frac{\Delta L_{2}}{L}\right) \cdot e_{2}
\end{gathered}
$$

If the decreased height of the damper unit due to its shear deformation is considered in more exact analysis, Eqs.(18) and (19) can be rewritten and $h_{2}$ has to be replaced by $\sqrt{h_{2}-\delta_{D}}$.

$$
\begin{aligned}
& e_{1}=\left(l+\delta_{D}\right) \cdot \sin (\theta-\alpha-\beta)-\sqrt{h_{2}^{2}-\delta_{D}^{2}} \cdot \cos (\theta-\alpha-\beta) \\
& e_{2}=\left(l-\delta_{D}\right) \cdot \sin \left(\theta+\alpha^{\prime}+\beta\right)-\sqrt{{h_{2}{ }^{2}-\delta_{D}^{2}}^{2}} \cdot \cos \left(\theta+\alpha^{\prime}+\beta\right)
\end{aligned}
$$

Differentiation of Eqs.(20)-(24) by the damper unit's shear deformation $\delta_{D}$ provides the following rate equations.

1) Differentiation of Eq.(29)

$$
\begin{aligned}
& \Delta \dot{L}_{1} \cos (\theta-\alpha)+\left(L+\Delta L_{1}\right) \sin (\theta-\alpha) \cdot \dot{\alpha}-0-0-\Delta \dot{L}_{2} \cos \left(\theta+\alpha^{\prime}\right) \\
& -\left(L-\Delta L_{2}\right) \sin \left(\theta+\alpha^{\prime}\right) \cdot \dot{\alpha}^{\prime}-l \sin \beta \cdot \dot{\beta}=0
\end{aligned}
$$

2) Differentiation of Eq.(30)

$$
\begin{aligned}
& 0-\Delta \dot{L}_{1} \cdot \sin (\theta-\alpha)+\left(L+\Delta L_{1}\right) \cdot \cos (\theta-\alpha) \cdot \dot{\alpha}-\Delta \dot{L}_{2} \cdot \sin \left(\theta+\alpha^{\prime}\right) \\
& +\left(L-\Delta L_{2}\right) \cdot \cos \left(\theta+\alpha^{\prime}\right) \cdot \dot{\alpha}^{\prime}-0-l \cdot \cos \beta \cdot \dot{\beta}=0
\end{aligned}
$$

3) Differentiation of Eq.(31)

$$
\begin{aligned}
& E A \cdot \frac{\Delta \dot{L}_{1}}{L} \cdot \cos (\theta-\alpha)+\left(P+E A \cdot \frac{\Delta L_{1}}{L}\right) \cdot \sin (\theta-\alpha) \cdot \dot{\alpha}+E A \cdot \frac{\Delta \dot{L}_{2}}{L} \cdot \cos \left(\theta+\alpha^{\prime}\right) \\
& +\left(P-E A \cdot \frac{\Delta L_{2}}{L}\right) \cdot \sin \left(\theta+\alpha^{\prime}\right) \cdot \dot{\alpha}^{\prime}+Q \cdot \sin \beta \cdot \dot{\beta}=\dot{Q} \cdot \cos \beta
\end{aligned}
$$

4) Differentiation of Eq.(32) 


$$
\begin{aligned}
& E A \cdot \frac{\Delta \dot{L}_{1}}{L} \cdot \sin (\theta-\alpha)-\left(P+E A \cdot \frac{\Delta L_{1}}{L}\right) \cdot \cos (\theta-\alpha) \cdot \dot{\alpha}-E A \cdot \frac{\Delta \dot{L}_{2}}{L} \cdot \sin \left(\theta+\alpha^{\prime}\right) \\
& +\left(P-E A \cdot \frac{\Delta L_{2}}{L}\right) \cdot \cos \left(\theta+\alpha^{\prime}\right) \cdot \dot{\alpha}^{\prime}+(2 P \cdot \sin \theta \cdot \sin \beta-Q \cdot \cos \beta) \cdot \dot{\beta}=\dot{Q} \cdot \sin \beta
\end{aligned}
$$

5) Differentiation of Eq.(33)

$$
E A \cdot \frac{\Delta \dot{L}_{1}}{L} \cdot e_{1}+\left(P+E A \cdot \frac{\Delta L_{1}}{L}\right) \cdot \dot{e}_{1}+E A \cdot \frac{\Delta \dot{L}_{2}}{L} \cdot e_{2}-\left(P-E A \cdot \frac{\Delta L_{2}}{L}\right) \cdot \dot{e}_{2}=0
$$

where

$$
\begin{aligned}
& \dot{e}_{1}=\sin (\theta-\alpha-\beta)-\left(l+\delta_{D}\right) \cdot \cos (\theta-\alpha-\beta) \cdot(\dot{\alpha}+\dot{\beta}) \\
& +\frac{\delta_{D}}{\sqrt{h_{2}{ }^{2}-\delta_{D}{ }^{2}}} \cdot \cos (\theta-\alpha-\beta)-\sqrt{h_{2}{ }^{2}-\delta_{D}{ }^{2}} \cdot \sin (\theta-\alpha-\beta) \cdot(\dot{\alpha}+\dot{\beta}) \\
& \dot{e}_{2}=-\sin \left(\theta+\alpha^{\prime}+\beta\right)+\left(l-\delta_{D}\right) \cdot \cos \left(\theta+\alpha^{\prime}+\beta\right) \cdot\left(\dot{\alpha}^{\prime}+\dot{\beta}\right) \\
& +\frac{\delta_{D}}{\sqrt{h_{2}^{2}-\delta_{D}^{2}}} \cdot \cos \left(\theta+\alpha^{\prime}+\beta\right)+\sqrt{h_{2}{ }^{2}-\delta_{D}{ }^{2}} \cdot \sin \left(\theta+\alpha^{\prime}+\beta\right) \cdot\left(\dot{\alpha}^{\prime}+\dot{\beta}\right)
\end{aligned}
$$

Substituting differentiated equations (32) and (33) considering the changed height of the damper unit due to its shear deformation, Eq.(31) can be rewritten as follows.

$$
\begin{aligned}
& E A \cdot \frac{\Delta \dot{L}_{1}}{L} \cdot e_{1}+E A \cdot \frac{\Delta \dot{L}_{2}}{L} \cdot e_{2} \\
& -\left(P+E A \cdot \frac{\Delta L_{1}}{L}\right) \cdot\left(l+\delta_{D}\right) \cdot \cos (\theta-\alpha-\beta) \cdot \dot{\alpha}-\left(P+E A \cdot \frac{\Delta L_{1}}{L}\right) \cdot\left(l+\delta_{D}\right) \cdot \cos (\theta-\alpha-\beta) \cdot \dot{\beta} \\
& -\left(P+E A \cdot \frac{\Delta L_{1}}{L}\right) \cdot \sqrt{h_{2}^{2}-\delta_{D}^{2}} \cdot \sin (\theta-\alpha-\beta) \cdot \dot{\alpha}-\left(P+E A \cdot \frac{\Delta L_{1}}{L}\right) \cdot \sqrt{h_{2}^{2}-\delta_{D}^{2}} \cdot \sin (\theta-\alpha-\beta) \cdot \dot{\beta} \\
& -\left(P-E A \cdot \frac{\Delta L_{2}}{L}\right) \cdot\left(l-\delta_{D}\right) \cdot \cos \left(\theta+\alpha^{\prime}+\beta\right) \cdot \dot{\alpha}^{\prime}-\left(P-E A \cdot \frac{\Delta L_{2}}{L}\right) \cdot\left(l-\delta_{D}\right) \cdot \cos \left(\theta+\alpha^{\prime}+\beta\right) \cdot \dot{\beta} \\
& -\left(P-E A \cdot \frac{\Delta L_{2}}{L}\right) \cdot \sqrt{h_{2}^{2}-\delta_{D}^{2}} \cdot \sin \left(\theta+\alpha^{\prime}+\beta\right) \cdot \dot{\alpha}^{\prime}-\left(P-E A \cdot \frac{\Delta L_{2}}{L}\right) \cdot \sqrt{h_{2}{ }^{2}-\delta_{D}{ }^{2}} \cdot \sin \left(\theta+\alpha^{\prime}+\beta\right) \cdot \dot{\beta} \\
& =-\left(P+E A \cdot \frac{\Delta L_{1}}{L}\right) \times\left\{\sin (\theta-\alpha-\beta)+\frac{\delta_{D}}{\sqrt{h_{2}^{2}-\delta_{D}^{2}}} \cdot \cos (\theta-\alpha-\beta)\right\} \\
& -\left(P-E A \cdot \frac{\Delta L_{2}}{L}\right) \times\left\{\sin \left(\theta+\alpha^{\prime}+\beta\right)-\frac{\delta_{D}}{\sqrt{h_{2}^{2}-\delta_{D}^{2}}} \cdot \cos \left(\theta+\alpha^{\prime}+\beta\right)\right\}
\end{aligned}
$$


In Eq.(43), $\Delta \dot{L}_{1}, \Delta \dot{L}_{2}, \dot{\alpha}, \dot{\alpha}^{\prime}, \dot{\beta}$ denote $d \Delta L_{1} / d \delta_{D}, d \Delta L_{2} / d \delta_{D}, d \alpha / d \delta_{D}, d \alpha^{\prime} / d \delta_{D}$, $d \beta / d \delta_{D}$ respectively. $\dot{Q}$ can be rewritten as

$$
\dot{Q}=\left(K_{e q}+K_{p l}\right)+\dot{K}_{e q} \cdot \delta_{D}
$$

In Eq.(44), $K_{p l}$ is the lateral stiffness of the vertical steel plate and $\dot{K}_{e q}$ is an equivalent stiffness of the high-hardness rubber differentiated by $\delta_{D}$.

$$
\begin{gathered}
K_{p l}=\frac{12 E I}{h_{2}{ }^{3}}+\frac{P \cdot \sin \theta}{H} \\
\dot{K}_{e q}=\frac{S}{t} \times\left[-0.62 \times 0.32 \times \delta_{D}{ }^{-1.62} \times t^{0.62}-0.1 \times 0.66 \times \delta_{D}{ }^{-1.66} \times t^{0.66}\right]
\end{gathered}
$$

The results of the incremental analysis will be compared with those of the spring model, the simple analysis model and the experiment in the following section.

\section{Experimental Verification}

\subsection{Outline of $1 / 1$-scale experimental verification}

In this section, the results for these analysis models, i.e. the spring model, the simple analysis model, the incremental analysis model, are compared with the results of the 1/1-scale experiment to examine the accuracy of these analysis methods and to investigate the vibration control effect of the proposed new vibration control system in the range of small amplitude.

To examine the vibration control effect of the proposed post-tensioning vibration control system, a quasi-static test was first performed for the specimen including the 1/1-scale damper unit. As shown in Fig.17, a loading frame in this test consists of the shaking table and the H-beam fixed on the strong reaction frame. A damper unit is installed with four braces in the loading frame. Each brace is connected to the corner of the damper unit and the T-beam fixed on the bottom of the H-beam by pinned connection. Post-tension can be introduced by turning a turnbuckle placed on the center of braces. The amount of post-tension is controlled by monitoring the strain gauges attached on the braces.

In this test, different kinds of structures are not considered because the main purpose of this test is to examine the basic performances of this system. However, different kinds of structures are needed to make the stress transferred in a wide range of deformation and make the construction easy when this system is installed into residential houses. Detailed joint methods are still under investigation.

One or two rubber plates $(25 \mathrm{~mm} \times 25 \mathrm{~mm} \times 3 \mathrm{~mm}$; high-hardness rubber or linear rubber) between two or three steel plates are inserted in the damper unit as shown in Figs.18(a), (b). One is the damper unit with a deformation magnification mechanism and the other is without. We also performed other experiments in the case where the amount of eccentricity of braces is changed. However, we deal with only one case of no eccentricity of braces in this paper. 


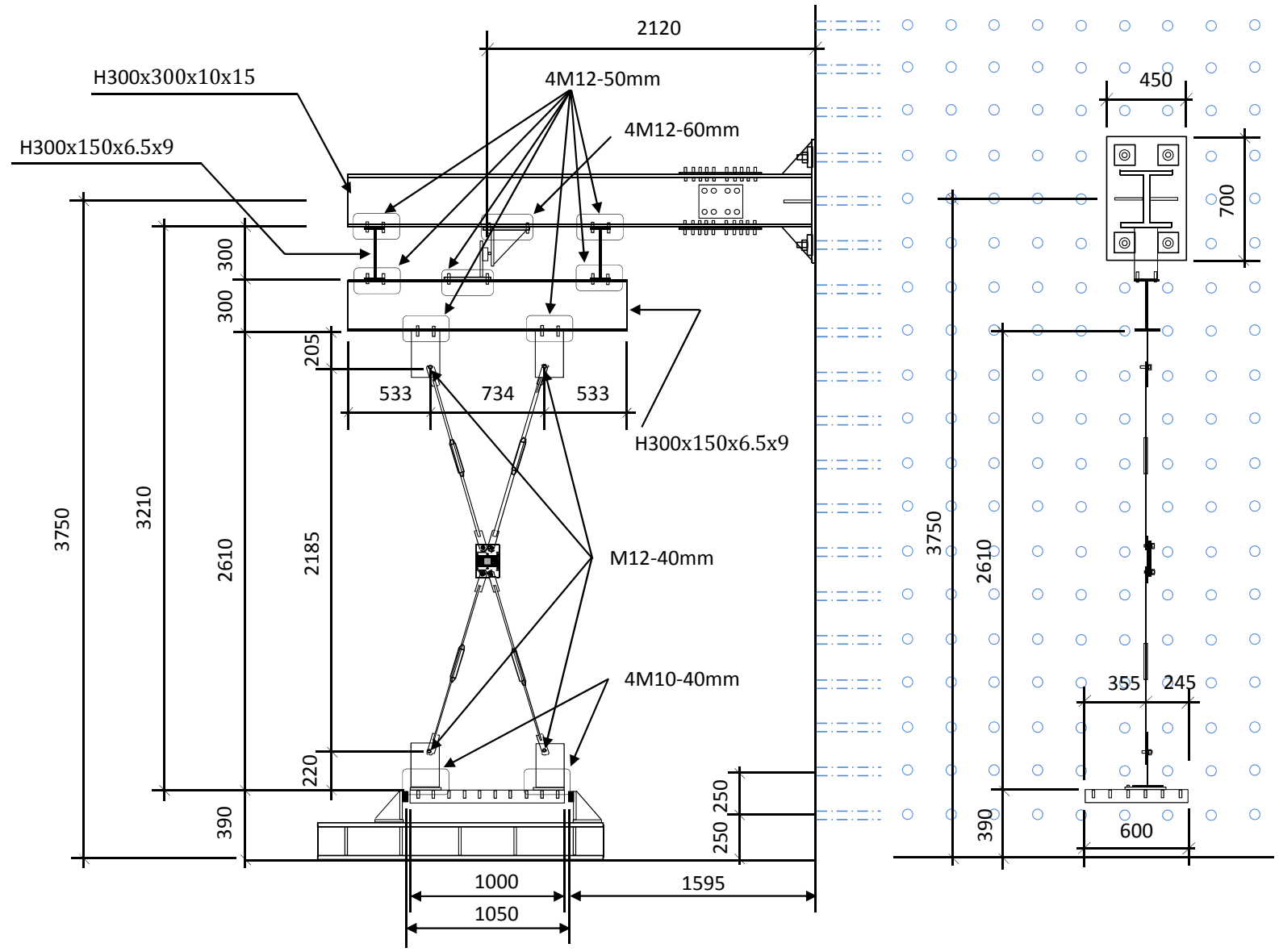

Fig.17 1/1-scale experimental specimen

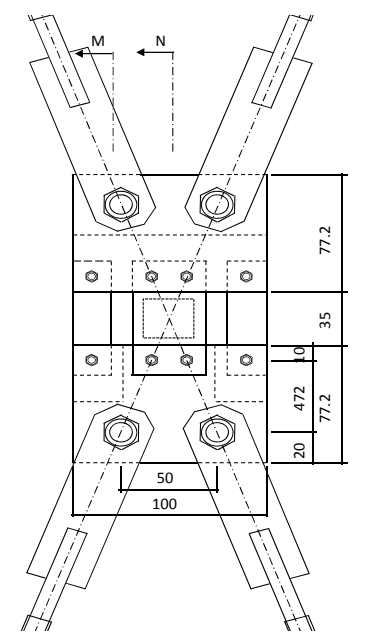

(a) Damper unit without deformation magnification mechanism

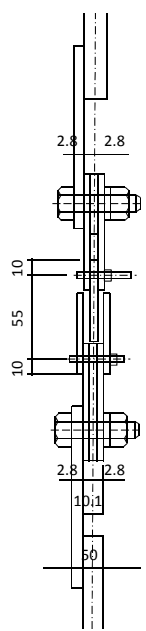

Fig.18 Detail of damper units

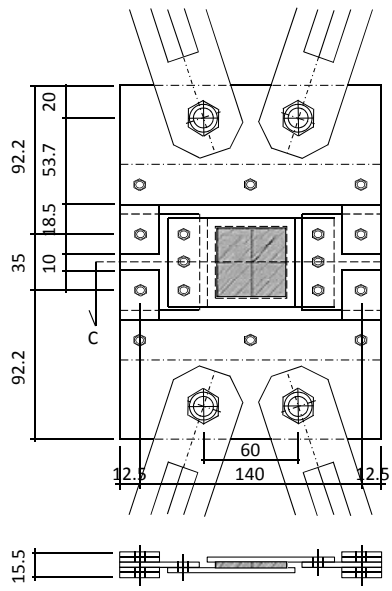

(b) Damper unit with deformation magnification mechanism 


\subsection{Comparison of analytical results with experimental results}

Experimental verification was performed on the two proposed vibration control systems including nonlinear high-hardness rubbers and linear rubbers, respectively (see Fig.18). The parameter values of the analysis models are taken from those of the experimental specimens.

Figs.19-22 show how experimental results including high-hardness rubbers (Fig.18(a)) correspond to those of the analysis, such as the elongation of braces, the rotational angle of the damper unit and the effective deformation ratio. In the experiment, the installation angle of braces was 1.25 radians (71.6 degrees) and the force of $850 \mathrm{~N}$ as a post-tension was introduced to the braces through turnbuckles. Figs.19 and 20 show the change of the elongation of braces in the tensile and compressive zones, respectively, when the frame deformation $\delta_{S}$ is $3 \mathrm{~mm}$. The initial elongation of the braces by the post-tension was $0.04 \mathrm{~mm}$. More than $3 \mathrm{~mm}$ of the frame deformation was not considered in the comparison because the brace in the compressive zone is affected by a buckling behavior after the loss of the post-tension. An effective analysis range enabling to compare the analytical results with the experimental results by the post-tension was determined in case of no eccentricity. The results of the spring model and the simple analysis model correspond well with the experimental results although these analysis models are not considering the buckling behavior. However, the errors of the results of the detailed analysis model and the incremental analysis model from the experimental results are about $0.01 \mathrm{~mm}$ even at $\delta_{S}=3 \mathrm{~mm}$. Therefore, introducing a post-tension larger than $850 \mathrm{~N}$ to the braces or an additional analysis on the buckling behavior is needed to compare the elongation of braces and other quantities in the range of more than $3 \mathrm{~mm}$ of the frame deformation.

Figs. 21 and 22 show the rotational angle of the damper unit and the effective deformation ratio, respectively. All analysis results exhibit large differences from the experimental results except the spring model without damper unit's rotation. These differences may be caused by friction forces at the connections and a small post-tension introduced into the high-hardness rubber damper system. These friction forces not only interrupt the rotation of the damper unit but also give negative effects on the braces. Therefore, other joint methods are needed to prevent the damper rotation and the reduction of the effective deformation ratio. Furthermore, a small post-tension makes the effective analysis range narrower, and fully affects the accuracy of the analysis models.

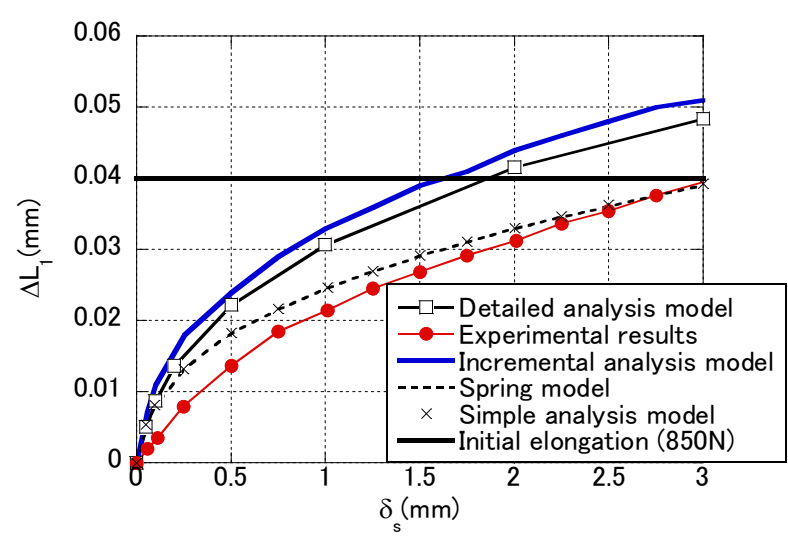

Fig.19 Elongation of the brace in tensile zone

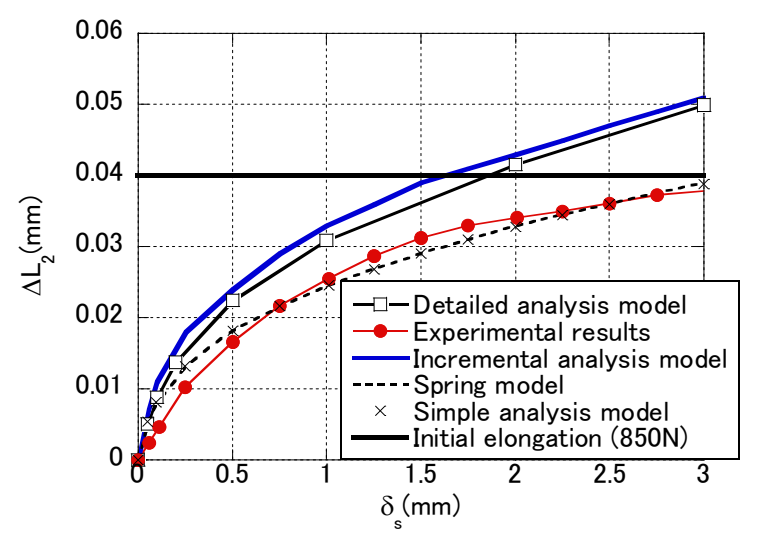

Fig.20 Elongation of the brace in compressive zone 


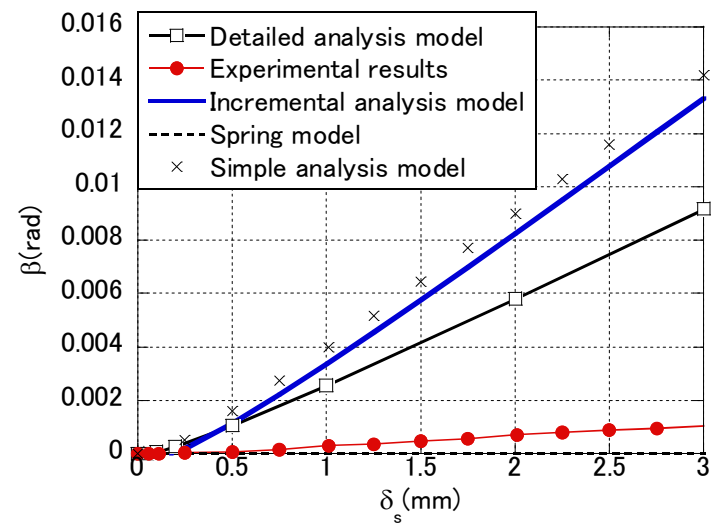

Fig.21 Rotational angle of the damper unit

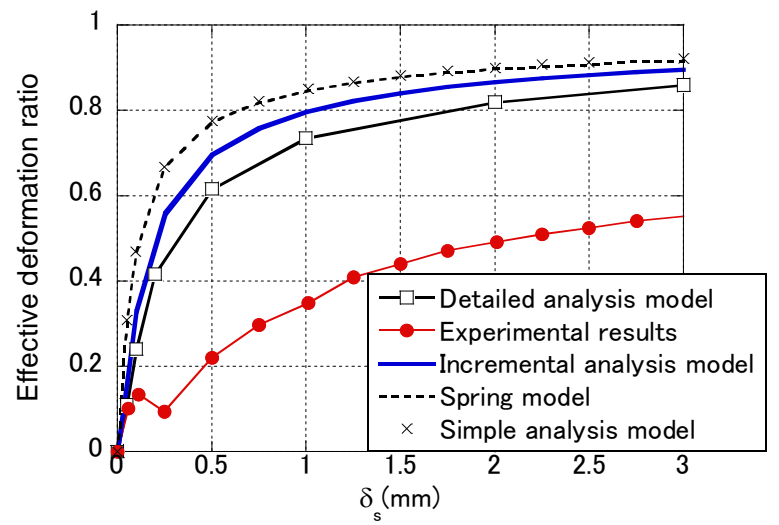

Fig.22 Effective deformation ratio

Under the same experimental conditions except the introduced post-tension, experimental verification was performed for the proposed vibration control system including linear rubbers as shown in Figs.17 and 18(b). In this comparison, the stiffness of the surrounding portion (upper beam and T-beam) connected to the braces was treated appropriately to analyze the elongation of braces more exactly. Here, $r_{k}$ is the stiffness coefficient of the surrounding portion to the brace. By multiplying the stiffness coefficient on the stiffness of the brace, more accurate analytical results could be obtained as shown in Figs.23-26. Here, the axial stiffness of the brace is $61541 \mathrm{~N} / \mathrm{mm}$. The relations among the stiffness $K_{S}$ of the surrounding portion, the stiffness $K_{b}$ of the brace, the equivalent stiffness $K_{b}{ }^{\prime}$ of the brace and the stiffness coefficient $r_{k}$ can be expressed as follows.

$$
\begin{gathered}
K_{S}=r_{k} \cdot K_{b} \\
K_{b}^{\prime}=\frac{1}{\frac{1}{K_{S}}+\frac{1}{K_{b}}}=\frac{r_{k}}{r_{k}+1} \cdot K_{b}
\end{gathered}
$$

We confirmed that the analysis results are more close to the experimental results by adopting an appropriate equivalent stiffness of the brace in the analysis models. Post-tension was lost more early although the introduced post-tension was $2000 \mathrm{~N}$ in the experiment. The effective analysis range was narrower than that in the first experiment. A triangular point on the $x$-axis in Fig.24 indicates the starting point that the post-tension is lost. In this experiment, the effective analysis range can be regarded as $0.88 \mathrm{~mm}$ of the frame deformation. Here, we can confirm that using the linear rubber having stiffness smaller than the nonlinear high hardness rubber in the post-tensioning vibration control system is not appropriate. Because it is difficult to capture the energy in the range of micro amplitudes caused by traffic and wind vibrations, a larger post-tension is needed to extend the effective analysis range. On the other hand, capturing the energy in the range of large amplitudes caused by earthquake is not provided by small post-tension. 


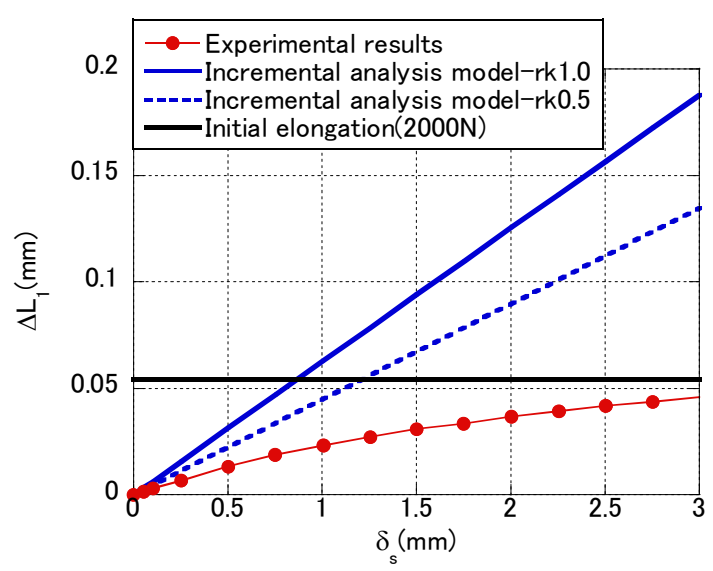

Fig.23 Elongation of brace in tensile zone

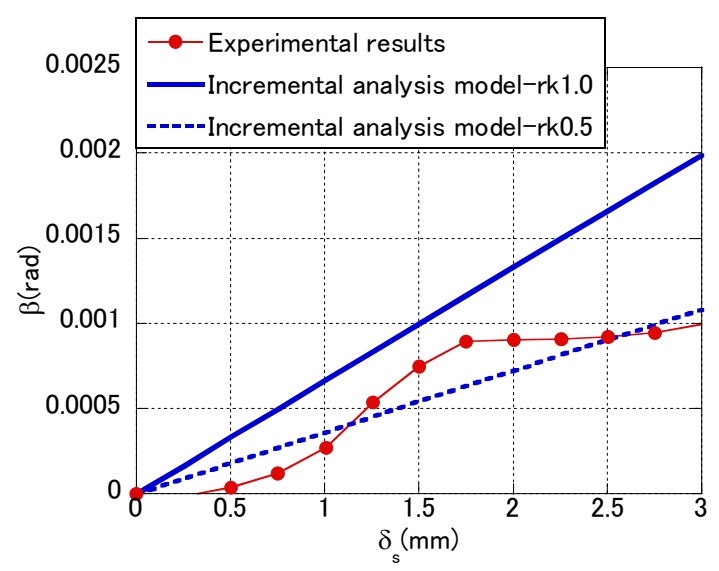

Fig.25 Rotational angle of the damper unit

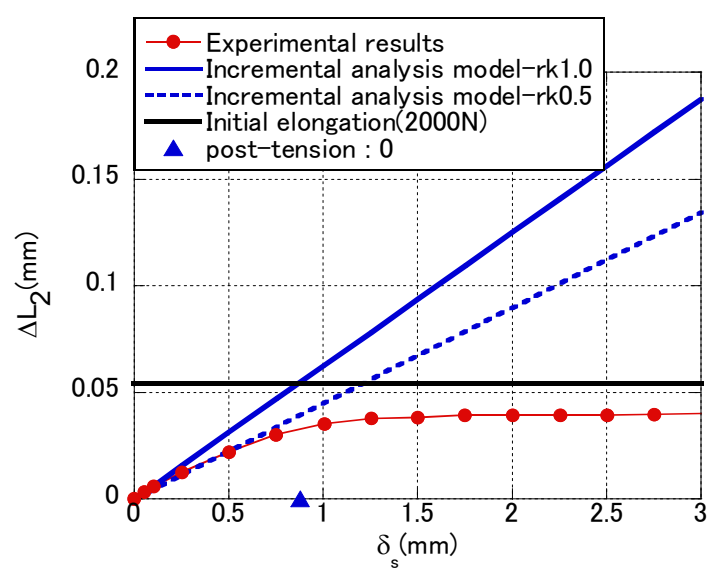

Fig.24 Elongation of brace in compressive zone

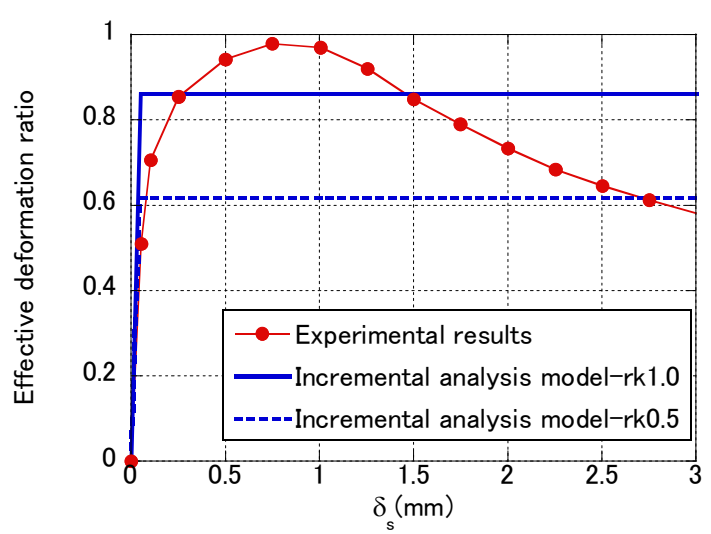

Fig.26 Effective deformation ratio

\section{Conclusions}

The following results have been obtained in this paper.

1) A new vibration control system has been proposed for residential houses which is handy and has an advantage of low cost, high safety and high-level habitability under traffic and wind vibrations.

2) Repetitive calculation using an equivalent linearization technique or incremental nonlinear analysis is needed to confirm the validity and accuracy of the effective deformation ratio. However, these analytical methods entail calculation load because the high hardness rubber has a nonlinear hysteretic characteristic. In this paper, a spring model without consideration of the rotation of the damper unit, a simple analysis model and an incremental analysis model have been proposed. The inverse problem analysis method has been established which can analyze the behavior of the damper unit or the deformation of the structural frame by prescribing the shear deformation of the high hardness rubber. 
3) An effective analysis range enabling to compare the analytical results with the experimental results by the introduced post-tension was determined in the case of no eccentricity of braces. After the loss of the post-tension, the buckling of braces occurs before their contraction. It is necessary to increase post-tension for improving the accuracy of the proposed analysis models.

4) Other joint methods are needed to prevent the reduction of the effective deformation ratio because the friction force acting at the connections has effects on the behaviors of the damper unit and braces.

5) It is more effective to use a nonlinear high-hardness rubber than a linear rubber in the post-tensioning vibration control system. This is because high-hardness rubbers are able to capture the energy in the range of micro amplitudes by traffic and wind vibration due to their large stiffness in small deformation range less than $5 \%$ of shear strain. On the other hand, it is confirmed from the experimental results that linear rubbers tend to be easily deformed with their primary structures by small external forces. Furthermore the post-tensioning damper system including linear rubbers needs to large post-tension to capture the energy in the range of large amplitudes caused by earthquakes.

\section{Acknowledgments}

The authors are grateful for the support of the GCOE program in Kyoto University (Human Security Engineering for Asian Megacities). This project is also partially supported by SRI Hybrid Corp. (Sumitomo Rubber Industry Corp. at present) and PanaHome Corp.

\section{References}

Aiken, ID., Nims, DK Whittaker, AS and Kelly, JM. (1993). "Testing of passive energy dissipation systems”, Earthquake Spectra, 9, 335-370.

Christopoulos, C., and Filiatrault, A. (2006). "Principle of Passive Supplemental Damping and Seismic Isolation”, IUSS Press, University of Pavia, Italy.

Hanson, R.D., and Soong, T.T. (2001). "Seismic Design with Supplemental Energy Dissipation Devices”, EERI, Oakland, CA.

Housner, G. et al. (1997). "Special issue, Structural control : past, present, and future”, J. Eng. Mech ASCE, 123(9), 897-971.

Min, K.-W., Kim, J., Lee, S.-H. (2004). "Vibration tests of 5-storey steel frame with viscoelastic dampers”, Eng. Struct., 26(6), 831-839.

Park, S.W. (2001). "Analytical modeling of viscoelastic dampers for structural and vibration control”, Int. J. Solids Struct., 38(44-45), 8065-8092.

Saidi, I. , Gad, E.F., Wilson, J.L. and Haritos, N. (2011). "Development of passive viscoelastic damper to attenuate excessive floor vibrations”, Eng. Struct., 33(12), 3317-3328.

Samali, B. and Kwok, K.C.S. (1995). "Use of viscoelastic dampers in reducing wind- and earthquake-induced motion of building structures”, Eng. Struct., 17(9), 639-654.

Soong, T.T., and Dargush, G.F. (1997). "Passive Energy Dissipation Systems in Structural Engineering”, John Wiley \& Sons, Chichester.

Soong, T.T., and Constantinou, M.C. (2002). "Passive and Active Structural Vibration Control in 
Civil Engineering”, CISM International Centre for Mechanical Sciences, Springer Verlag.

Suzuki, C., Tsuji, M., Yoshitomi, S., Takewaki, I. and Matsumoto, T. (2007). "Experimental Study on Wind-induced Response Reduction Effect of High-Hardness rubber damper”, Summaries of Technical Papers of Annual Meeting, AIJ, B-2, 611-612. (in Japanese)

Takewaki, I (2009). Building Control with Passive Dampers: -Optimal Performance-based Design for Earthquakes-, John Wiley \& Sons Ltd. (Asia).

Tani, T., Tsuji, M., Yoshitomi, S., Takewaki, I. and Matsumoto, T. (2008). "Strain and frequency dependence of high-hardness rubber in the range from very small up to large displacement”, J. Struct. Constr. Eng., AIJ, 73, 1079-1086. (in Japanese)

Tani, T., Yoshitomi, S., Tsuji, M. and Takewaki, I. (2009). "High-performance control of wind-induced vibration of high-rise building via innovative high-hardness rubber damper”, J. Struct. Design of Tall and Special Buildings, 18(7), 705-728.

Tsuji, M., Fujuwara, Y., Murata, S., Kim, H.G., Yoshitomi, S. and Takewaki, I. (2010). "Post-tensioning damper system for micro-vibration reduction in residential houses: Analysis of effective deformation ratio by a simplified model”, J. Struct. Eng., AIJ, 56B, 171-178 (in Japanese).

Tsuji, M., Murata, S., Yoshitomi, S. and Takewaki, I. (2009). "Post-tensioning Damper System for Micro-vibration Reduction in Houses”, JSSC Journal of Constructional Steel, 17, 127-132 (in Japanese).

$\mathrm{Xu}$, ZD., Shen, YP., and Zhao, HT. (2003). "A synthetic optimization analysis method on structures with viscoelastic dampers”, Soil Dyn. Earthquake Eng., 23, 683-689.

$\mathrm{Xu}, \mathrm{Z} .-\mathrm{D} .$, Zhao, H.-T. and Li, A.-Q. (2004). "Optimal analysis and experimental study on structures with viscoelastic dampers”, J. Sound Vib., 273(3), 607-618.

Zhang, R.H., and Soong, T.T. (1992). "Seismic design of viscoelastic dampers for structural applications”, J. Struct. Eng., ASCE, 118(5), 1375-1392. 